\title{
Panorama da Participação Feminina em Competições de Programação Promovida por Instituição de Ensino Superior da Região Norte
}

\author{
Marcela Sávia Picanço Pessoa $^{1,2}$, Sérgio Cleger Tamayo², Eder Martins Franco² \\ ${ }^{1}$ Escola Superior de Tecnologia - Universidade do Estado do Amazonas (EST/UEA) \\ Manaus - AM - Brasil \\ ${ }^{2}$ Faculdade Fucapi \\ Manaus - AM - Brasil \\ msppessoa@uea.edu.br, sergio.cleger@gmail.com, efranco23@gmail.com
}

\begin{abstract}
This paper presents the impact of the realization of local computer events as a method to increase the interest of the students in programming competitions. Analyzing a brief history of the female participation in these competitions, this work discusses the reasons related to the low representation of woman in this segment, a problem which is beyond local frontiers, following a world trending, and presents some actions taken to change this scenery in a private university from Manaus.
\end{abstract}

Resumo. Este artigo apresenta o impacto da realização de eventos científicos locais como um método para aumentar o interesse dos alunos em competições de programação. Analisando um breve histórico da participação feminina nestas competições, este trabalho discute as razões relacionadas à baixa representação da mulher neste segmento, um problema que está além das fronteiras locais, seguindo uma tendência mundial, e apresenta algumas ações tomadas para mudar esse cenário em uma universidade particular de Manaus.

\section{Introdução}

A Computação é uma área com predominante presença masculina. Esta característica é presente também nas escolhas de ensino superior. Segundo o INEP (2014), somente $29,8 \%$ dos ingressantes no ensino superior que optam por cursos na área de Ciências, Matemática e Computação são do sexo feminino, e dentre estes somente 15\% optam pelos cursos de computação [Nunes, SBC 2015] [Oliveira et al., 2014].

É possível observar esta tendência em atividades que envolvem participação em competições tecnológicas, como Maratonas de Programação e Hackatonas. Em 2015, durante a realização da final mundial da competição organizada pela ICPC-ACM, foi comemorado um avanço de $1500 \%$ no número de participantes, quando comparado ao ano de 1997. Nesta edição participaram 384 competidores, sendo somente 9 do sexo feminino, representando $2 \%$ do total de participantes [ICPC-ACM, 2016].

Esta realidade se repete no Brasil, inclusive na Região Norte, mas existem várias iniciativas na tentativa de minimizar esta diferença [Freitas et al., 2016] [Lauschner et 
al., 2016]. Neste contexto, a Faculdade Fucapi ${ }^{1}$, uma universidade privada de Manaus AM, a partir de 2012, começou a desenvolver ações acadêmicas que, de forma indireta, incentivaram a participação de meninas em competições. Neste artigo é apresentado um diagnóstico com base na participação de mulheres em competição de programação tecnológica de um evento científico regional e algumas ações que foram desenvolvidas para contribuir com a mudança do cenário em questão na Faculdade Fucapi.

\section{Cenário anterior}

Até o ano de 2011 a Faculdade Fucapi participava da Maratona de Programação [MP, 2016], parte do International Contest Programming Contest da Association of Computing Machinery (The ICPC-ACM) [ICPC-ACM, 2016], e geralmente era representada por uma equipe onde não havia mulheres entre os membros. Por não haver políticas de incentivo à participação dos alunos neste tipo de competição, as equipes eram formadas a partir de convites de professores interessados em engajar os alunos em atividades extraclasses que ajudassem a desenvolver suas habilidades em programação.

A Universidade Federal do Amazonas sempre foi a única instituição a sediar a competição e desenvolve um trabalho de conscientização da importância deste tipo atividade para a formação acadêmica, porém, é perceptível a dificuldade em envolver instituições privadas na competição. Diante deste cenário, a Faculdade Fucapi definiu políticas para aumentar o número de alunos em competições e de eventos científicos. Entre estas políticas está a organização do Encontro Regional de Computação e Sistemas de Informação (ENCOSIS ${ }^{2}$ ), evento que no ano de 2017 está em sua sexta edição e tem o apoio da SBC. O diferencial deste evento é que as principais atividades da sua programação estão concentradas no turno noturno, buscando incentivar também alunos de instituições privadas da região norte a participarem de maneira mais efetiva em eventos que estimulem a produção científica. Uma das atividades principais do evento é a realização de uma Maratona de Programação, como descrita a seguir.

\section{Maratona de Programação do ENCOSIS}

A Competição de Programação do ENCOSIS segue os moldes da Maratona de Programação [MP, 2016]. Este tipo de competição conta com equipes de três alunos, que devem resolver uma quantidade de problemas em um intervalo de tempo, vencendo o desafio a equipe que responder mais questões no menor intervalo de tempo. Além disso, essas competições buscam promover a criatividade, a capacidade de trabalho em equipe, a busca de novas soluções de software e a habilidade de resolver problemas sob pressão, todas elas características necessárias também aos profissionais de informática.

O objetivo inicial da competição proposta pelo ENCOSIS era aumentar a participação de estudantes de instituições privadas nas competições de programação tecnológicas. Porém, ao tomar conhecimento do Programa Meninas Digitais, da SBC [Maciel, 2016] em 2013, reforçado pelo Cunhatã Digital [Lauschner et al., 2016], decidiu-se analisar a participação feminina nas competições do ENCOSIS. Foram

\footnotetext{
${ }^{1}$ www.fucapi.br

${ }^{2}$ www.encosis.com.br
} 
analisados dois aspectos: 1) comparação de competidores por sexo e 2) comparação de participantes do sexo feminino por instituição de ensino (particular ou pública), como segue.

\subsection{Análise dos Competidores por Sexo}

Em sua primeira edição, a Maratona de Programação do ENCOSIS (2012) contou com a participação de 27 equipes, compostas por alunos de 6 instituições diferentes. Dos 81 competidores somente 12 eram mulheres, representando 14,8\% do total de participantes. Este comportamento se repetiu nos próximos 4 anos, como mostra o Gráfico 1. Observa-se que o maior percentual de participação de competidores do sexo feminino aconteceu em 2014 e, ainda assim, este percentual não chegou a $20 \%$.

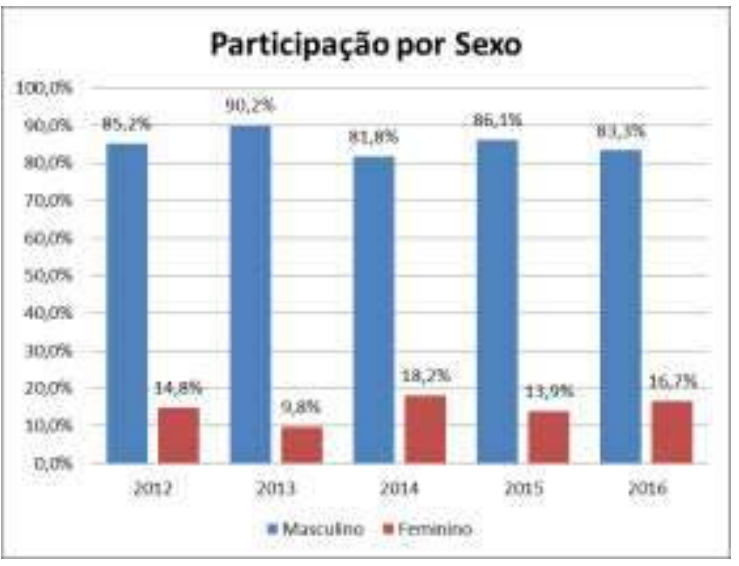

Gráfico 1 - Participantes por sexo na Maratona de Programação do ENCOSIS.

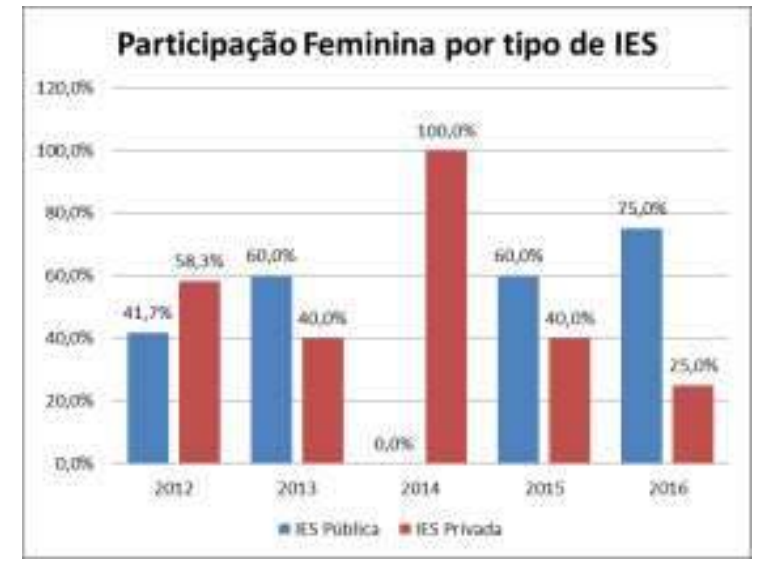

Gráfico 2 Participação Feminina
por IES Públicas e Privadas.

\subsection{Análise de Competidores do sexo Feminino por tipo de Instituição}

Considerando a observação de que a minoria de competidores é do sexo feminino e resgatando o objetivo inicial da maratona de programação do ENCOSIS, fez-se uma análise da participação feminina dividindo-a em dois grupos: Instituições de Ensino Superior (IES) Públicas e Privadas.

No Gráfico 2 é possível observar que a participação feminina entre as IES é equivalente. Porém é importante destacar que no ano de 2014 houve uma diminuição de $40 \%$ no número de equipes participantes de IES Públicas, e não houve representantes femininos entre as equipes. Somente 5 meninas competiram e todas eram da Faculdade Fucapi, instituição promotora do evento, que é privada. Já em relação ao sexo masculino, a participação das IES públicas é quase o dobro da participação das IES privadas. Um outro ponto que se observou é que dentre os participantes, na maioria dos casos, as mulheres participaram somente em uma edição, já a maioria dos homens participa em mais de uma edição (30\% das equipes).

Posto isto, em 2014 deu-se início a um trabalho de incentivo à participação de meninas da Faculdade Fucapi em competição de programação, como mostra a seção seguinte. 


\section{Estratégia para inserção de alunas em competições de programação}

Na tentativa de aumentar a participação de alunas da Faculdade Fucapi em competições de programação, desenvolveu trabalhos baseados em duas etapas:

\section{Inclusão}

Nesta etapa foi realizado um conjuntos de atividades para incentivar as alunas a participarem de competições tecnológicas. Entre as atividades estão: 1) Encontros para conversas informais e palestras motivacionais com pesquisadores, competidores, excompetidores e treinadores; 2) Inclusão, na programação do ENCOSIS, de atividades relacionadas à participação de meninas na área de tecnologia, em parceria com o Movimento Cunhatã Digital [Lauschner et al., 2016]; 3) Palestras na Faculdade Fucapi para ressaltar o papel da mulher no mundo da computação; e 4) Promoção de atividades de competições individuais;

\section{Treinamento}

Nesta etapa buscou-se desenvolver um conjunto de atividades direcionadas ao desenvolvimento de habilidades individuais e em grupo, necessárias para a participação em competições, tais como: 1) Sugestões sobre ambientes de competições a todos os novos integrantes do grupo; 2) Orientações e dinâmicas para composição de equipes (desde a chegada de novos membros até a definição das equipes que participaram das competições); 3 ) Orientação sobre técnicas de trabalho em equipe.

\section{Considerações Finais}

Este artigo apresentou um diagnóstico a respeito da participação feminina nas Maratonas de Programação do ENCOSIS. Como base nesse diagnóstico e incentivado pelos Programas Meninas Digitais [Maciel, 2016] e Cunhatã Digital [Lauschner et al., 2016] da SBC, foram propostas ações para incentivar a participação de alunas da Faculdade Fucapi em competições de programação tecnológicas, através da criação de um evento científico, como uma Maratona de Programação. Uma das conquistas do ENCOSIS foi aumentar a participação de estudantes da Faculdade Fucapi na Maratona de Programação [MP, 2016] uma vez que a partir de 2012 a instituição participou de todas as edições com no mínimo três equipes.

Quando considera a participação feminina, a partir de 2014, início das ações descritas neste artigo, sempre tem integrantes do sexo feminino nas equipes representantes da Faculdade Fucapi na Maratona de Programação [MP, 2016]. No ano de 2014 a instituição participou com uma equipe só de meninas e neste mesmo ano, foi a única instituição a ter representantes femininos na Maratona de Programação do ENCOSIS, conforme apresentado no Gráfico 2. O objetivo inicial de divulgar e gerar cultura de competições de programação em IES privadas não foi alcançado uma vez que nas últimas duas edições houve uma redução no número de instituições privadas participantes. Porém, observou-se o aumento de número de equipes na etapa regional da Maratona de Programação [MP, 2016].

Uma outra observação em relação à Faculdade Fucapi é que foi crescente a participação de mulheres nas competições de programação do ENCOSIS. No ano de 2014, 100\% das competidoras são da Faculdade Fucapi e nos anos de 2015 e 2016, 50\% 
das meninas participantes são da Faculdade Fucapi. Nas próximas edições do evento, pretende-se fazer um trabalho de incentivo à participação de mulheres de tal forma que estes percentuais de participação aumentem - não só na instituição promotora como em outras IES - e, com o tempo, trabalhar a melhoria no desempenho, uma vez que na metodologia utilizada não se analisou o desempenho. Entre as ações estão programadas palestras dentro e fora da instituição, criação de grupos de estudo para treinamento de competidores, uma maratona somente feminina e avaliações diagnósticas.

\section{Agradecimentos}

Um agradecimento especial ao Projeto Cunhatã Digital pela disponibilidade em participar de atividades do ENCOSIS e pela parceria nas últimas edições, em especial à professora Rosiane de Freitas Rodrigues, da Universidade Federal do Amazonas, não só pela atuação no projeto Cunhatã Digital como também pela histórica atuação, na região norte, no que diz respeito a competições de programação tecnológicas, sendo a maior incentivadora deste trabalho.

\section{Referências}

Freitas, R. et al (2016) "Projeto SciTechGirls: desenvolvimento de aplicativos e participação em competições de programação científicas e tecnológicas" In: XXXVI Congresso da Sociedade Brasileira de Computação 2016, Porto Alegre, p 2723-2727.

ICPC-ACM (2016). International collegiate programming contest. Association for Computing Machinery (ACM). Disponível em https://icpc.baylor.edu/.

Lauschner, T. et al. (2016). "Cunhantã Digital: programa de incentivo à participação de mulheres da região amazônica na Computação e áreas afins". In XXXVI Congresso da Sociedade Brasileira de Computação 2016, Porto Alegre, p 2656-2660.

Maciel, C., Bim, S. A. (2016) Programa Meninas Digitais - ações para divulgar a Computação para meninas do ensino médio, In: Computer on the Beach 2016, Florianópolis, SC, pp.327-336.

MP (2016). Maratona de programação. The ICPC-ACM South America - Brazil. Sociedade Brasileira de Computação. Disponível em http://maratona.ime.usp.br/.

Nunes, D.J. (2015) "Educação Superior em Computação Estatísticas - 2015". http://www.sbc.org.br/documentos-da-sbc/category/133-estatisticas.

Oliveira, A.C. et al. (2014) "Perfil Feminino em Computação: Análise Inicial", In: XXXIV Congresso da Sociedade Brasileira de Computação - CSBC 2014, Brasília, WEI - XXII Workshop sobre Educação em Computação, p 1465-1474.

Sinopse Estatística da Educação Superior, (2014) http://portal.inep.gov.br/sinopsesestatisticas-da-educacao-superior.

Site da Sociedade Brasileira de Computação. "Programa Meninas Digitais da Sociedade Brasileira de Computação (SBC) incentiva participação de mulheres no mercado de TI” http://www.sbc.org.br/noticias/1855-programa-meninas-digitais-da-sociedadebrasileira-de-computacao-sbc-incentiva-participacao-de-mulheres-no-mercado-de-ti. 